\title{
THE
}

\section{Datana drexelii (Lepidoptera: Notododontidae) occurrence and larval survival on highbush blueberry cultivars}

\author{
Alex K. Baranowski \\ University of Rhode Island \\ Steven R. Alm \\ University of Rhode Island, stevealm@uri.edu \\ Evan L. Preisser \\ University of Rhode Island, preisser@uri.edu
}

Follow this and additional works at: https://digitalcommons.uri.edu/bio_facpubs

The University of Rhode Island Faculty have made this article openly available.
Please let us know how Open Access to this research benefits you.

This is a pre-publication author manuscript of the final, published article.

Terms of Use

This article is made available under the terms and conditions applicable towards Open Access Policy Articles, as set forth in our Terms of Use.

\section{Citation/Publisher Attribution}

Baranowski, A.K., Alm, S.R., and E.L. Preisser. 2020. Datana drexelii (Lepidoptera: Notododontidae) oviposition and larval survival on highbush blueberry cultivars. Journal of Economic Entomology, 113(3), 1568-1571. doi: 10.1093/jee/toaa050

Available at: https://doi.org/10.1093/jee/toaa050 
1

13

14

15

16

17

18
Alex Baranowski

Department of Biological Sciences

University of Rhode Island

Woodward Hall

9 East Alumni Avenue

Kingston, RI 02881 USA

(860) 378-7430

alexbaran74@gmail.com

Datana drexelii (Lepidoptera: Notododontidae) occurrence and larval survival on highbush

\section{blueberry cultivars}

4

$$
\text { ALEX K. BARANOWSKI }{ }^{1 *} \text {, STEVEN R. ALM }{ }^{2} \text {, and EVAN L. PREISSER }{ }^{1}
$$

15

6

${ }^{1}$ Department of Biological Sciences, University of Rhode Island, Kingston, RI 02881

${ }^{2}$ Department of Plant Sciences and Entomology, University of Rhode Island, Kingston, RI 02881 


\section{Abstract}

Plant genotype influences plant suitability to herbivores; domesticated plants selected for

21 properties such as high fruit yield may be particularly vulnerable to herbivory. Cultivated strains

22 of highbush blueberry, Vaccinium corymbosum L. can be high-quality hosts for larvae of the

23 gregariously-feeding notodontid Datana drexelii (Hy. Edwards). We conducted an experiment

24 assessing $D$. drexelii larval survival and pupal weight when fed foliage from five blueberry

25 cultivars: 'Bluecrop', 'Bluetta', 'Blueray', 'Lateblue', and 'Jersey'. We complemented this

26 experimental work with repeated bush-level surveys of a managed blueberry patch for naturally

27 occurring $D$. drexelii larval clusters. Larval survival and pupal weight were significantly higher

28 on 'Lateblue' foliage than from the 'Bluecrop', 'Bluetta', and 'Jersey' cultivars. The blueberry

29 patch surveys found more D. drexelii larval clusters on 'Bluehaven', 'Collins', and 'Darrow'

30 bushes than on the cultivars 'Earliblue' and 'Jersey'. The low D. drexelii occurrence and

31 performance on the 'Jersey' cultivar suggests that this variety may be appropriate for areas where

32 this pest is common; conversely, their high occurrence on 'Bluehaven' 'Collins', and 'Darrow'

33 suggests that these cultivars may be particularly vulnerable. Cultivar-level variation in herbivore

34 vulnerability highlights how understanding plant-pest interactions can help manage agricultural 35 species.

$36 \quad$ Keywords

37 Herbivory, preference, performance, defoliator 


\section{Introduction}

Herbivore fitness is influenced by host plant phenotype. Although wild plants experience strong selection for herbivore tolerance and/or resistance, domesticated plants are subjected to different pressures. Selection for high fruit yield in domesticated plants, for example, can reduce plant defense against herbivores (Sanchez-Hernandez et al. 2006, Turcotte et al. 2014, Hernandez-Cumplido et al. 2018). Larvae of Lymantria dispar L. (Lepidoptera: Erebidae) grow more quickly and have lower mortality when reared on domesticated versus wild-type Vaccinium corymbosum L. (Hernandez-Cumplido et al. 2018). Wild-type tomatoes (Solanum lycopersicum L.) produce more phenolic compounds than domesticated ones (Sanchez-Hernandez et al. 2006), and growth rate of the moth Manduca sexta L. (Lepidoptera: Sphingidae) is negatively correlated with such phenolics (Stamp and Yang 1996, Yang and Stamp 1996).

Vaccinium corymbosum (hereafter 'blueberry') is a deciduous ericaceous plant native to North America grown commercially for its fruits. As with other agricultural plants, blueberry has multiple cultivars that have been selected for yield, flavor, or pest/disease resistance (Lobos and Hancock 2015, Clift et al. 2017, Rodriguez-Saona et al. 2019). Cultivar-related differences in herbivore growth and mortality have been recorded in lepidopteran species such as Streblote panda (Hübner, 1820) (Lepidoptera: Lasiocampidae) (Calvo and Molina 2010), and tephritid flies such as Bactrocera dorsalis (Hendel), Ceratitis capitata (Wiedemann, 1824) (Follett et al. 2011) and Rhagoletis mendax (Curran) (Liburd et al. 1998).

Members of the notodontid genus Datana (Walker, 1855) are defoliating pests of agricultural, silvicultural, and horticultural crops (Cutler and Harris 1979, Harris 1983). Datana drexelii (Hy. Edwards) (hereafter 'Datana') is a native defoliating pest of ericaceous plants in the genera Vaccinium L. and Gaylussacia (Kunth). Females lay clusters of up to 200 eggs on 
61 suitable host plants; their gregarious nature, combined with the fact that larvae can reach six $\mathrm{cm}$

62 in length, make it an especially destructive pest (Wagner 2005). While this insect does not

63 directly attack fruit, its defoliation of blueberry bushes reduces the following year's flowering

64 and subsequent fruit crop (Lyrene 1992, Williamson and Miller 2000). We reared Datana larvae

65 on different blueberry cultivars and measured their survival to pupation and pupal weight. In

66 addition, we repeatedly surveyed a patch planted with multiple blueberry cultivars for naturally-

67 occurring clusters of Datana larvae. Together, the data reveal substantial differences in Datana

68 preference for and occurrence on different blueberry cultivars.

\section{Materials and Methods}

Performance Assay: In June 2019, we mated adults from a lab colony of Datana drexelii, reared on wild-type $V$. corymbosum, in an outdoor emergence cage at the University of Rhode

72 Island's East Farm research facility (Kingston, RI). We collected their eggs and assigned five

73 each to $946 \mathrm{~mL}$ polypropylene cups (Pactiv LLC, Lake Forest, IL). Each cup was randomly

74 assigned to one of five blueberry cultivars: 'Bluecrop', 'Blueray', 'Bluetta', 'Jersey', or

75 'Lateblue'. There were 22-23 replicate cups per cultivar. Eggs in a given cup generally hatched

76 on the same day; in three cups one day, and in one cup two days, elapsed between the emergence

77 of the first and last hatchling. Host foliage from the appropriate cultivar was added to the cup

78 immediately following emergence of the first hatchling. Larvae received four-leaf sections of

79 foliage from current year's growth (as indicated by soft, green bark); no other leaf position

80 standardization was done. Prior to adding foliage to each container, each piece was dipped in a

$812 \%$ bleach $(=0.1 \% \mathrm{NaOCl})$ solution and allowed to air dry; this measure was taken to decrease

82 the threat posed by pathogenic fungi and bacteria (Trivedy et al. 2011). Foliage was replaced 
Four days after the last hatchling in a given cup eclosed, we weighed all hatchlings

together and counted the number of larvae and unhatched eggs. The total number of hatched larvae was our starting number of larvae for a cup, regardless of how many eggs hatched. We used this data to calculate post-hatching survival. Larvae were subsequently counted and weighed together each week; we recorded the date each larva entered the prepupal phase. Prepupae were left in cups until all larvae in a cup reached such a state or died. When all prepupae had either died or become pupae, each pupa was sexed, weighed and then held in a $6 \mathrm{~L}$ polypropylene bin (Sterilite Corp, Townsend, MA) of moist coconut coir for overwintering. Occurrence Assay: In summer 2019, we conducted a six-week Datana survey of an East Farm blueberry patch enclosed in bird-proof netting that did not exclude insects. The patch consisted of 240 bushes arranged in eight rows of 30 bushes. The cultivars represented (numbers of bushes in parentheses) were ‘Bluecrop' (25), 'Bluegold' (5), 'Bluehaven’ (15), 'Bluejay’ (15), 'Blueray' (15), 'Bluetta' (15), 'Chandler' (5) ‘Collins' (20), 'Darrow' (20), 'Earliblue' (30), 'Herbert' (15), 'Jersey' (15), 'Lateblue' (15), 'Northland' (15), and 'Reka' (15). Cultivars were arranged in five-bush groups within a given row.

Between July $16^{\text {th }}$ and August $26^{\text {th }}$, we conducted 15 total censuses (with as many as nine days and as few as one day between censuses) for Datana larval clusters. We walked on both sides of each bush and scanned for larval clusters. We spent a minimum of thirty seconds per bush and longer if necessary and recorded the number of larval clusters on each bush before removing them from the bush. Following the final census, we measured the height and maximum width of each bush.

Statistical Analysis: For the performance assay, mean pupal weight and percent survival (average per cup) to pupation were analyzed using analysis of covariance (ANCOVA), with 
107 'cultivar' as the main effect and 'hatch date' and, because we were concerned about sex-

108 mediated performance differences, 'number of female pupae per cup' as covariates. We excluded

10915 cups in which only a single larva hatched, leaving a total of 98 cups (=replicates). When the

110 ANCOVA revealed a significant main effect, we used Tukey's HSD tests $(\alpha=0.05)$ to

111 differentiate between treatment. We also conducted an overall linear correlation analysis between

112 weight and survival across all cultivars.

113 For the occurrence assay, we summed the total number of larval clusters counted per

114 bush over the fifteen censuses. Prior to analysis, we removed data from two cultivars, 'Bluegold'

115 and 'Chandler', only represented by a single five-bush cluster within the patch; all other cultivars

116 were each represented by between three and six five-bush clusters. During our surveys, we

117 noticed that small ( $\sim .5 \mathrm{~m}$ in height) recently-planted bushes had virtually no larval clusters

118 regardless of their cultivar. We addressed this bias by excluding bushes below the $10^{\text {th }}$ percentile

119 in height $(0.7 \mathrm{~m})$ from the analysis; this excluded 27 bushes from five cultivars but only two of

120108 larval clusters. We used GLMM (poisson distribution with log-link function) to analyze the

121 203-bush data set. The model was generated with the main effect 'cultivar' and the blocking

122 variables 'row' and 'column' as random effects; 'bush height' was included as a covariate. The

123 GLMM was initially run using both blocking variables; the non-significant blocking variable

124 'row' was then removed and the resulting GLMM re-run. When the GLMM revealed a

125 significant main effect of 'cultivar', we used likelihood-ratio $\chi$-square tests $(\alpha=0.05$; controlled

126 for type 1 errors due to multiple comparisons) to differentiate between treatments.

127 All analyses were performed using JMP 9.0.0 (SAS 2010).

$128 \quad$ Results 
Performance Assay: Larvae reared on 'Lateblue' pupated at nearly three times the weight

130

of larvae reared on 'Blueray', 'Bluetta', and 'Jersey' $\left(0.375 \mathrm{~g}\right.$ versus $0.127 \mathrm{~g}$, respectively; $F_{4,91}$ $=3.18, P=0.017$; Fig. 1A). Survival to pupation was also higher on 'Lateblue' than on 'Bluecrop', 'Bluetta', and 'Jersey' (16.9\% versus 5.1\%; $F_{4,91}=3.62, P=0.009$; Fig. 1B). Hatch date affected survival, with later-hatching larvae having higher mortality $\left(F_{1,91}=7.84, P=\right.$ 0.006). The number of female pupae per cup was correlated with both weight at and survival to pupation (both $P<0.001$ ). There was a significant cultivar-level correlation between mean pupal weight and mean survival to pupation $\left(\mathrm{R}^{2}=0.84, F_{1,3}=15.6, P=0.029\right)$.

Occurrence Assay: We found a total of 108 Datana larval clusters over the six-week course of the survey. The distribution of larval clusters over time was as follows: 14 on July $16^{\text {th }}$, ten on July $18^{\text {th }}, 35$ on July $22^{\text {nd }}$, one on July $23^{\text {rd }}$, five on July $25^{\text {th }}$, three on July $26^{\text {th }}$, one on July $29^{\text {th }}$, two on July $30^{\text {th }}$, two on July $31^{\text {st }}, 11$ on Aug. $1^{\text {st }}, 12$ on Aug. $2^{\text {nd }}$, one on Aug. $6^{\text {th }}$, two on Aug. $11^{\text {th }}$, eight on Aug. $20^{\text {th }}$, and one on Aug. $26^{\text {th }}$. Cultivars differed in Datana colonization (L-R $\chi^{2}=28.01$ with $12 \mathrm{df}, \mathrm{p}=0.006$; Fig. 2), with 'Bluehaven', 'Collins', and 'Darrow' having more Datana clusters (1.00/bush, $0.75 /$ bush, and $0.85 /$ bush, respectively) than either 'Jersey' or 'Earliblue' ( 0.13 and 0.07 per bush, respectively). Neither bush height ( $L-R \chi^{2}=0.52$ with $1 \mathrm{df}, \mathrm{p}$ $=0.47)$ nor column ( $\mathrm{L}-\mathrm{R} \chi^{2}=39.3$ with $\left.29 \mathrm{df}, \mathrm{p}=0.096\right)$ affected Datana colonization.

\section{Discussion}

Datana larval performance in the lab did not overlap with field observations. Despite high larval performance on 'Lateblue', larval occurrence on it was not the highest on this cultivar in the field survey. High Datana densities on 'Bluehaven', 'Collins', and 'Darrow', cultivars not included in our performance assay, suggest they may be particularly suitable to this pest. In contrast, both occurrence and performance were significantly lower for 'Earliblue' and 'Jersey' 
152 than other tested cultivars (Figs. 1, 2). This implies that 'Earliblue' and 'Jersey' may have 153 antixenotic and antibiotic effects on Datana.

Mortality in the performance assay occurred mostly within a week of hatching, when

155 larvae were small and inconspicuous. Our high early larval mortality across treatments could indicate that either cultivated blueberry is unsuitable for this species (comparison to wild-type

157 blueberry is needed to determine this), or perhaps that the unnaturally low early instar densities could be reducing the feeding ability, and thus survival, of hatchlings (Dave Wagner, pers. comm). It is also possible that the quality of the cut blueberry may diminish more quickly than 160 the foliage is replaced (within $24 \mathrm{hrs}$ instead of 3 days), malnourishing larvae. If similarly high

161 levels of hatchling mortality also occurred in the field survey, we could have missed some 162 oviposition events when all larvae died prior to reaching a detectable size. Because of this, the 163 patterns in our field survey data likely reflect some combination of female oviposition preference 164 and plant resistance to early-instar larval feeding. While most larval clusters contained a similar 165 number (10-20 individuals) of small $2^{\text {nd }}-3^{\text {rd }}$ instar larvae, we failed to detect some clusters until they contained $4^{\text {th }}-5^{\text {th }}$ instar larvae. The laboratory-based oviposition choice tests necessary to 167 isolate the role of female preference may be complicated by this species' habit of readily 168 ovipositing on container walls and other artificial objects.

Our work could be extended to comparisons of Datana interactions with cultivated versus 170 wild-type blueberry, as well as with other Vaccinium species. Selective breeding for pest 171 resistance (Lobos and Hancock 2015) and the incorporation of several related Vaccinium species 172 into V. corymbosum cultivars (Lobos and Hancock 2015) may alter the cultivar's suitability to 173 Datana. Both 'Lateblue' and 'Jersey', cultivars on which larvae did the best and worst, are pure 174 V. corymbosum, but 'Bluecrop' is 4\% Vaccinium angustifolium (Aiton, 1789) and 'Bluetta' is 
$17528 \%$ V. angustifolium. Some cultivars are only $42 \%$ V. corymbosum and contain genes from up

176 to five other species (Lobos and Hancock 2015). Intrageneric variation in herbivore

177 susceptibility has been described for other Vaccinium (Ieri et al. 2013) species as well as for

178 genera ranging from Asclepias L. (Waterbury et al. 2019) to Quercus L. (Rieske and Dillaway

179 2008).

180 In summary, there were blueberry cultivar-related differences in occurrence and

181 performance of this blueberry defoliator. This information could prove useful for cultivar

182 selection in areas where this pest becomes a major problem, and highlights how understanding

183 plant-pest interactions can help reduce the need for costly chemical or mechanical (removal of

184 individual larval clusters) treatments. 
185

186

187 Requintina, and L. Varkonyi assisted with oviposition surveys. M. Goldsmith provided helpful 188

\section{Acknowledgements}

D. Vadnais assisted with larval rearing, and O. Barsoian, D. Butler, C. Johnson, M.

comments on an earlier version of this manuscript. 
Calvo, D., and J. M. Molina. 2010. Differences in foliage affect performance of the lappet moth, Streblote panda: Implications for species fitness. Journal of Insect Science 10: 177.

Clift, A. D., G. Murdoch, and S. Mansfield. 2017. Blueberry cultivars differ in susceptibility to the elephant weevil, Orthorhinus cylindrirostris (Coleoptera: Curculionidae). J. Econ. Entomol. 110: 2259-2262.

Cutler, B. L., and M. K. Harris. 1979. Foliage consumption and damage by the walnut caterpillar on pecan in Texas USA. J. Econ. Entomol. 72: 315-318.

Follett, P. A., F. T. Zee, R. T. Hamasaki, K. Hummer, and S. T. Nakamoto. 2011. Susceptibility of low-chill blueberry cultivars to mediterranean fruit fly, oriental fruit fly, and melon fly (Diptera: Tephritidae). J. Econ. Entomol. 104: 566-570.

Harris, M. K. 1983. Outbreak biology of walnut caterpillar Datana integerrima in Texas USA. Southwest. Entomol. 8: 231-240.

Hernandez-Cumplido, J., M. M. Giusti, Y. Zhou, V. Kyryczenko-Roth, Y. H. Chen, and C. RodriguezSaona. 2018. Testing the 'plant domestication-reduced defense' hypothesis in blueberries: the role of herbivore identity. Arthropod-Plant Interactions 12: 483-493.

leri, F., S. Martini, M. Innocenti, and N. Mulinacci. 2013. Phenolic distribution in liquid preparations of Vaccinium myrtillus L. and Vaccinium vitis idaea L. Phytochem. Anal. 24: 467-475.

Liburd, O. E., S. R. Alm, and R. A. Casagrande. 1998. Susceptibility of highbush blueberry cultivars to larval infestation by Rhagoletis mendax (Diptera: Tephritidae). Environ. Entomol. 27: 817-821.

Lobos, G. A., and J. F. Hancock. 2015. Breeding blueberries for a changing global environment: a review. Frontiers in Plant Science 6: 782.

Lyrene, P. M. 1992. Early defoliation reduces flower bud counts on rabbiteye blueberry. HortScience 27: 783-785.

Rieske, L. K., and D. N. Dillaway. 2008. Response of two oak species to extensive defoliation: Tree growth and vigor, phytochemistry, and herbivore suitability. For. Ecol. Manage. 256: 121-128.

Rodriguez-Saona, C., C. Vincent, and R. Isaacs. 2019. Blueberry IPM: past successes and future challenges, pp. 95-114. In A. E. Douglas (ed.), Annual Review of Entomology, Vol 64, vol. 64.

Sanchez-Hernandez, C., M. G. Lopez, and J. P. Delano-Frier. 2006. Reduced levels of volatile emissions in jasmonate-deficient $\mathrm{spr}_{2}$ tomato mutants favour oviposition by insect herbivores. Plant Cell and Environment 29: 546-557.

SAS 2010. JMP user's guide, version 9.0 computer program, version By SAS, Cary NC.

Stamp, N. E., and Y. Yang. 1996. Response of insect herbivores to multiple allelochemicals under different thermal regimes. Ecology 77: 1088-1102.

Trivedy, K., S. N. Kumar, N. Vinutha, and S. Qadri. 2011. In vitro testing of common disinfectants used in sericulture to control the growth of fungi in rearing houses. Research Journal of Microbiology 6: 439-465.

Turcotte, M. M., N. E. Turley, and M. T. Johnson. 2014. The impact of domestication on resistance to two generalist herbivores across 29 independent domestication events. New Phytol. 204: 671681.

Wagner, D. L. 2005. Caterpillars of Eastern North America, Princeton University Press, Princeton, NJ 08540.

Waterbury, B., A. Potter, and L. K. Svancara. 2019. Monarch butterfly distribution and breeding ecology in Idaho and Washington. Frontiers in Ecology and Evolution 7: 172.

Williamson, J. G., and E. P. Miller. 2000. Early fall defoliation of southern highbush blueberry inhibits flower bud initiation and retards flower bud development. HortScience 35: 505. 
235 Yang, Y., and N. E. Stamp. 1996. Simultaneous effects of temperature and multiple allelochemicals on 236 the performance of a Solanaceae specialist caterpillar (Manduca sexta). Ecoscience 3: 81-92. 
240 survival to pupation (B) when reared on five different Vaccinium corymbosum cultivars. Bars

241 with different uppercase letters are significantly different (Tukey's HSD at $\alpha=0.05$ ).

243 cultivars over the course of six weeks and fifteen censuses. Cultivars in dark blue were included

244 in the performance assay (Fig. 1). Bars with different uppercase letters are significantly different 245 (Tukey's HSD at $\alpha=0.05$ ). 


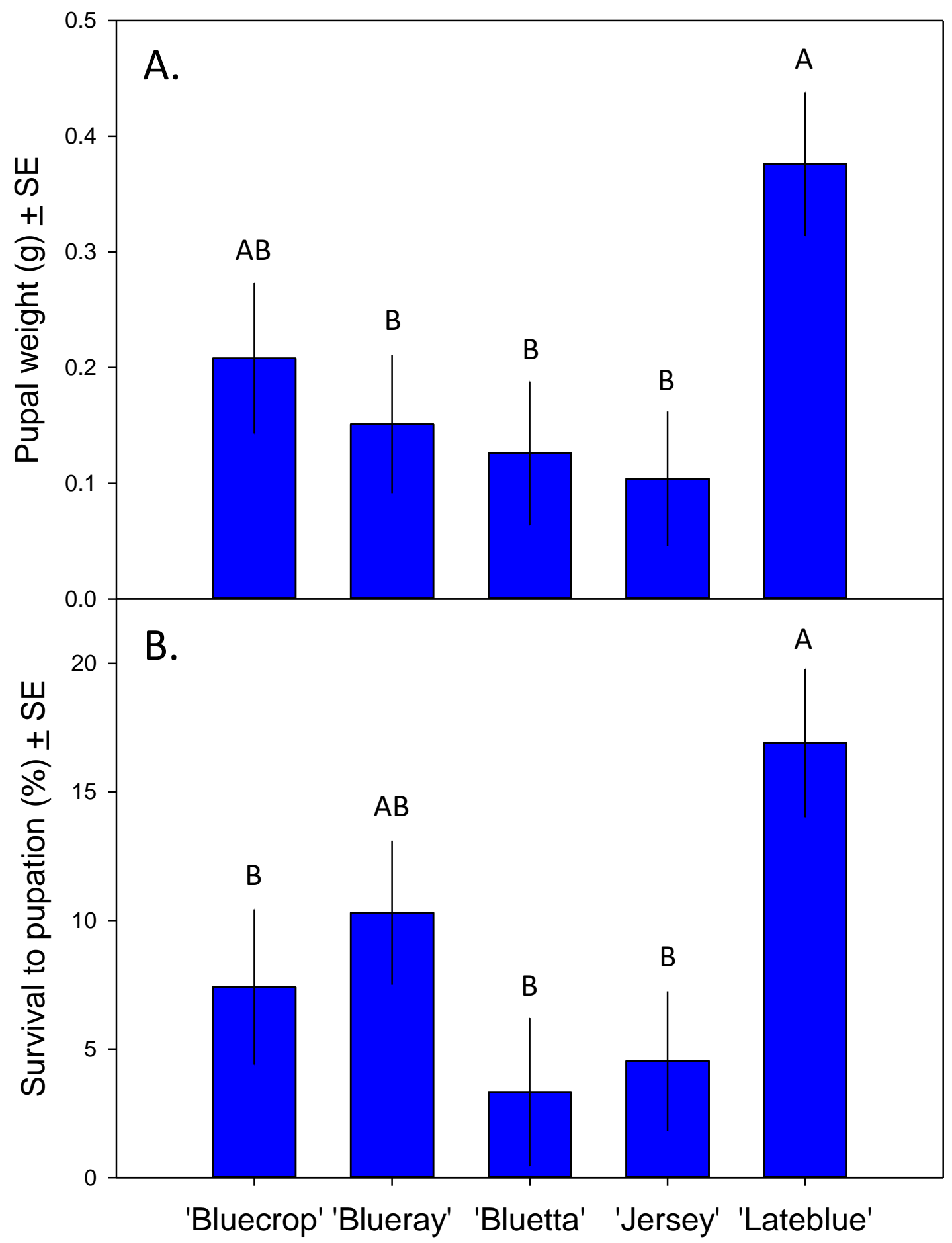


Figure 2.

248

249

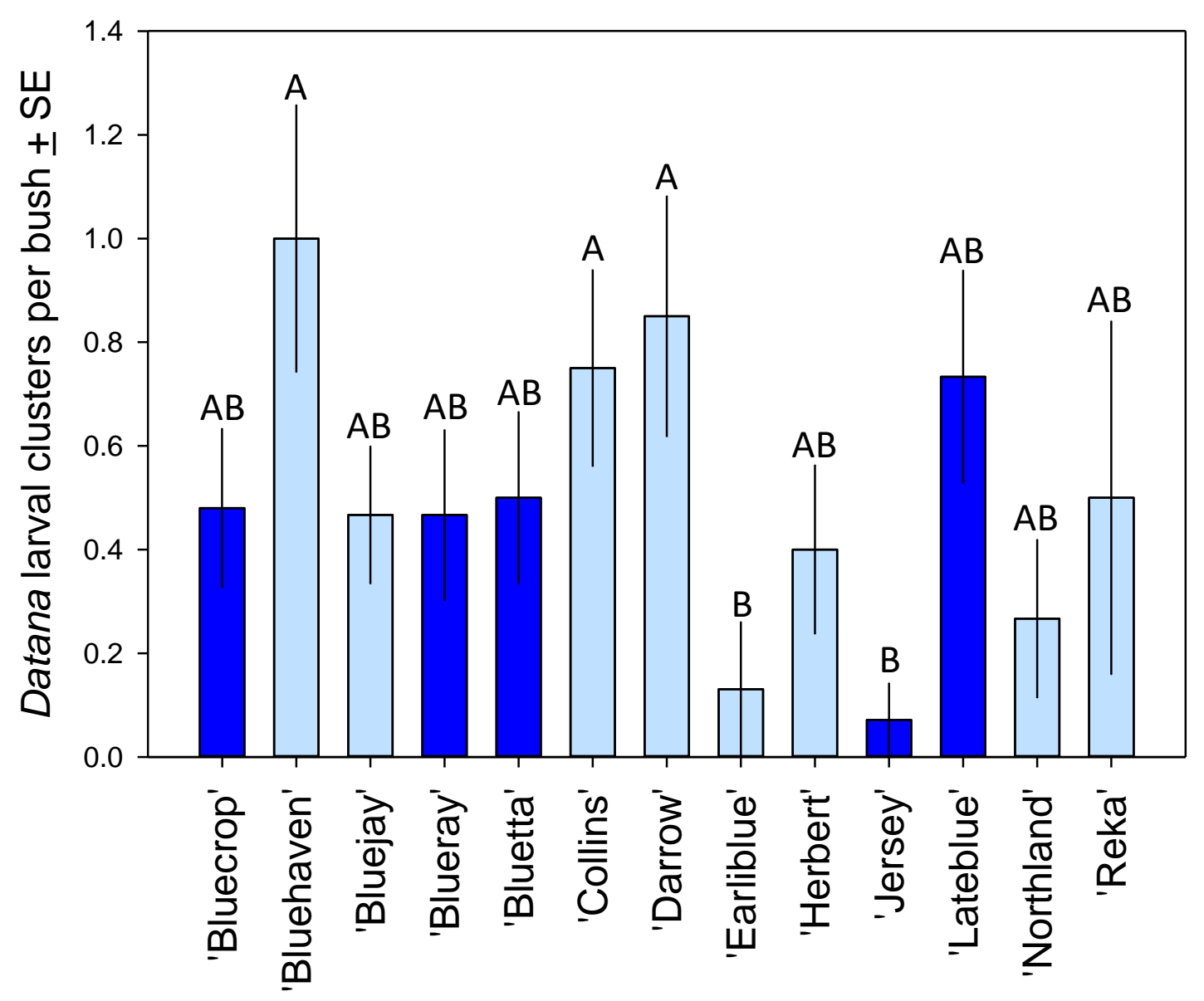

